\title{
The Estimation and Mitigation of Agricultural Greenhouse Gas Emissions from Livestock
}

\author{
Clark H \\ New Zealand Agricultural Greenhouse Gas Research Centre \\ Private Bag 11008, Palmerston North 4442, New Zealand \\ harry.clark@nzagrc.org.nz
}

\begin{abstract}
Emissions of methane (CH4) and nitrous oxide (N2O) from agricultural activities currently comprise $10-12 \%$ of the world's total anthropogenic greenhouse gas (GHG) emissions. They are also forecast to rise by $30 \%$ above current levels by 2050 . At the Conference of the United Nations Framework Convention on Climate Change (UNFCCC) held in Paris in December 2015, more than 100 countries indicated that they would reduce agricultural GHG emissions as part of the global effort to keep warming to a maximum of $2^{\circ} \mathrm{C}$. Emissions from ruminant livestock present a particular challenge as enteric $\mathrm{CH} 4$ emissions alone comprise $~ 40 \%$ of total agricultural emissions. Estimating emissions from animal agriculture can be done through simple estimates, generically available data on animal populations and regional-level fixed emission factors per animal. But these estimates are subject to very large uncertainties and their appropriateness for estimating emissions at the country level is questionable. More appropriate country-specific methods can be developed using local data and expert opinion in the first instance, even in the absence of countryspecific emission factors. Reducing GHG emissions from ruminant livestock is challenging technically even if livestock production is constant, and is particularly challenging if the sector is increasing in size. Internationally the quantity of GHG produced per unit of product has been declining consistently and for both cattle meat and milk than 50 years ago. This decline is largely due to increased efficiency of production. Increasing efficiency is therefore a key component of agricultural GHG mitigation. Increasing efficiency, while essential, may not be enough on its own. New technologies are therefore needed and for ruminant livestock there are some promising products; compounds that inhibit enteric $\mathrm{CH} 4$, vaccines, low emitting sheep have been successfully bred and, a variety of low emitting feeds, and feed additives.
\end{abstract}

Key Words: Livestock Emissions, Inventory, Emissions Estimates, Production Efficiency, Emissions Mitigation

\section{INTRODUCTION}

Current estimates are that emissions of methane $\left(\mathrm{CH}_{4}\right)$ and nitrous oxide $\left(\mathrm{N}_{2} \mathrm{O}\right)$ from agricultural activities comprise $10-12 \%$ of the world's total anthropogenic greenhouse gas (GHG) emissions (Smith et al. 2014). If emissions of carbon dioxide from agricultural activities, for example fuel use, and land use change are taken into account this estimate rises to close to a quarter of all anthropogenic emissions (Smith et al. 2014). At the $21^{\text {st }}$ session of the Conference of the Parties to the United Nations Framework Convention on Climate Change (UNFCCC) held in Paris in December 2015, more than 100 countries indicated that they would take steps to reduce agricultural GHG emissions as part of the global effort to keep warming to a maximum of $2^{\circ} \mathrm{C}$, although details on how countries are going to achieve these reductions are scarce. Emissions associated from ruminant livestock present a particular challenge since alone they are estimated to make up close to $70 \%$ of all agricultural greenhouse gas emissions (Smith et al. 2014). 


\section{HOW ARE LIVESTOCK EMISSIONS ESTIMATED?}

\section{Global estimates}

Globally, there are three independent sources of disaggregated non- $\mathrm{CO}_{2}$ emissions from livestock: The United States Environmental Protection Agency (US EPA), Electronic Database Gathering, Analysis and Retrieval system (EDGAR) and Food and Agriculture Organization Statistics (FAOSTAT) (Smith et al. 2014). These three approaches tend to rely on FAOSTAT activity data and use IPCC Tier 1 approaches. The IPCC (Smith et al. 2014) concluded that although these three sources give slightly different estimates, they are statistically consistent given the uncertainties inherent in the data sources and IPCC default methodologies. All three databases agree that the largest emitting category is enteric methane ( 40\%) with manure management making up a further 7-8\%, manure deposited on pasture $(\sim 15 \%)$ and synthetic fertiliser, much of which is used for the production of livestock feed, a further $12 \%$. These top down estimates have the advantage that they utilise common methodologies and common published data sources but they have the strong disadvantage that for any particular country they may not be utilising either the most comprehensive data sources or a methodology that fully reflects local circumstances. For example, the EDGAR database reports enteric fermentation emissions from New Zealand in 1990 being 1.27 Mt but the New Zealand's Greenhouse Gas Inventory Report 1990-2014 (Ministry for the Environment 2016) reports them as being 1.05 Mt.

\section{Country estimates using IPCC approaches}

National GHG inventories are reported under the UNFCCC using the technical guidelines and good practice methodologies developed by the IPCC (IPCC 2006). Inventories will play an important role in assessing how individual countries are meeting their nationally determined commitments (NDC). All countries will be required to report their emissions at least every two years.

The IPCC describe three different levels of complexity for inventory reporting: Tier 1, Tier 2, and Tier 3. Tier 1 estimates require few resources as they can be constructed using IPCC default values and publicly available data. They are also likely to be the least accurate and are unlikely to reflect a country's unique national circumstances. Advanced inventories (Tier 2 and Tier 3) require more detailed data but they are likely to be more accurate as they can capture country-specific circumstances. The distinction between Tier 2 and Tier 3 is somewhat imprecise and Tier 3 is perhaps best thought of as a more country-tailored version of a Tier 2 inventory.

Tier 1 inventories basically only require two pieces of information, a quantity (e.g. nitrogen fertiliser use, animal numbers) and an emission factor (e.g. $\mathrm{CH}_{4} / \mathrm{cow} /$ year). Tier 1 livestock inventories estimate emissions by multiplying the total number of animals in a livestock category (dairy, non-dairy cattle, sheep, goats, buffalo, etc.) with a fixed emission factor. IPCC default emission factors are generally estimated for an entire continent (e.g. Asia, Oceania) and given the wide diversity of livestock systems across large continents their relevance for an individual country is questionable. Simple Tier 1 inventories constructed using fixed emission factors have no ability to capture changes in farming practice and animal performance and cannot incorporate mitigation actions other than changes in livestock populations. These are serious weaknesses given that livestock production systems and the performance of animals within them can both change substantially over time. 
Tier 2 and Tier 3 livestock are not dissimilar to Tier 1 inventories in their broad structure in that they require quantities and emission factors but these quantities and emission factors are country specific and disaggregated. For example, a Tier $2 / 3$ enteric methane inventory will use country specific data on an animal's performance to estimate gross energy or dry matter intake, may well categorise each livestock species by age, physiological status and gender and then use these data, along with a methane yield factor that may vary according to the type of animal, production system and the environment. Energy or dry matter intake (DMI) is estimated from local productivity data (such as live weight gain, milk yield and feed quality), population data will be locally sourced and updated regularly, and methane per unit of energy or intake will reflect, as far as possible, the type of feed being consumed. Methane emissions for each category of animal would then be intake/gross energy $\times$ methane yield $\times$ population. A Tier 2-based inventory will change as animal performance changes and as population number and structure change. It far more accurately reflects a country's actual production systems and productivity, the influence these have on estimated emissions, and can better capture any mitigation actions.

\section{HOW MUCH INFLUENCE DOES THE METHOD OF ESTIMATION HAVE ON REPORTED EMISSIONS?}

New Zealand has a large agricultural sector and reports using a Tier $2 / 3$ inventory developed specifically to reflect local circumstances (MfE 2016). In Table 1, enteric methane emissions for dairy cattle reported to the UNFCCC in 2016 are compared with a Tier 1 estimate that uses the same total population data but the default IPCC Oceania emission factor and Tier 1 estimates from the FAOSTAT database (www.faostat3/browse/ G1/GE/E). All three show that emissions have increased over time but using the Oceania default value has higher estimated values in 1990 to 2010 while the FAOSTAT values are consistently lower than the values reported to the UNFCCC by New Zealand in 2000 to 2014. The same exercise for sheep shows that Oceania default values and FAOSTAT values are the same and that they produce figures that are 17-33\% lower than those reported in the New Zealand inventory (data not presented).

Table 1. Enteric methane emissions from dairy cattle in New Zealand estimated using three different approaches

\begin{tabular}{|c|c|c|c|c|}
\hline \multirow[t]{2}{*}{ Year } & Population & $\begin{array}{l}\mathrm{NZ} \text { reported } \\
\text { emissions }\end{array}$ & $\begin{array}{l}\text { Estimated using Oceania default } \\
\text { value of } 81 \mathrm{~kg} / \mathrm{animal} / \mathrm{year}\end{array}$ & $\begin{array}{c}\text { FAOSTAT } \\
\text { database }\end{array}$ \\
\hline & $(000)$ & \multicolumn{3}{|c|}{ 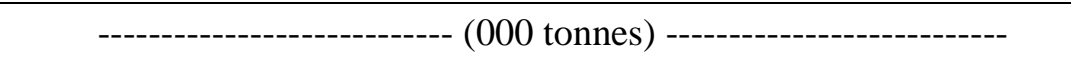 } \\
\hline 1990 & 3,441 & 238 & 279 & 245 \\
\hline 2000 & 4,598 & 350 & 372 & 300 \\
\hline 2010 & 5,915 & 467 & 479 & 421 \\
\hline 2014 & 6,698 & 550 & 543 & 438 \\
\hline
\end{tabular}

\section{THE BENEFITS OF USING ADVANCED INVENTORIES}

Moving to more complex, country specific information improves an inventory's accuracy. It may or may not reduce the uncertainty since this will depend crucially on how uncertain the country specific data being used are; higher Tier inventories require more data, each of which comes with its own uncertainty. A higher Tier inventory will highlight where the uncertainties are, and improve the transparency and accuracy of GHG emissions reporting. Sensitivity analysis can also be used to help prioritise investment in the 
collection of data. The inventory can also be used as a forecasting tool for estimating with greater accuracy the GHG implications of changes in agricultural practice and the size of the agricultural sector. Many of important statistics needed for a Tier 2 inventory, such changes in fertiliser use, animal performance and systems of production, are the same statistics used to drive and monitor the success of agricultural development plans.

Productivity in agriculture changes over time and there has been a downward trend in the emissions produced per unit of product in all sectors (Smith et al. 2014). For example, as animals improve their productivity, emissions per animal tend to increase but their emissions per unit of product (e.g. per kilogram of milk) go down because a smaller proportion of the food they eat is used for maintenance. If Tier 1 inventory approaches are used, any estimates of this GHG efficiency benefit (reduced emissions intensity) cannot be captured since emission factors are, by definition, constant over time even when the amount of product produced per animal is not constant. Tier 2 and Tier 3 inventory approaches can accurately capture these efficiency benefits, which may be increasingly important for countries with large agricultural sectors that are trying to balance food security and rural development with making a contribution to agricultural GHG mitigation; decreased emissions intensity is likely to be a strong co-benefit of general development programmes.

A higher Tier inventory is by its nature more detailed than a Tier 1 inventory but these higher tier inventories can be developed over time and for many countries an initial Tier 2 inventory can be constructed by adopting a simple structure that uses a minimal in-country dataset. It will be better than the alternative of a Tier 1 inventory that uses a regional default emission factor and assumes implicitly that productivity remains fixed over time. However, it must be recognised that the development of an accurate agricultural GHG inventory will need investment in both personnel and, if local emission factors are to be developed, measurement equipment.

\section{MITIGATING LIVESTOCK EMISSIONS}

Reducing GHG emissions from livestock is technically challenging even if livestock production is constant. It is particularly challenging if the sector is increasing in size, for example, due to a growing domestic demand for animal products or where exporting livestock products is a key component of economic development. FAO have estimated that by 2050 the demand for meat and milk will to grow by 73 and $58 \%$, respectively, from their levels in 2010 (FAO 2011). The quantity of GHG produced per unit of product has been declining consistently (Smith et al. 2014) for all agricultural products but based on historical changes it will not be enough to offset the increased amount of product produced.

The mitigation of agricultural greenhouse gases also has to be placed in context. Production systems vary widely as does the social, environmental, technical and economic context. Mitigation needs to be appropriate to the local circumstances and take account of the social and poverty dimension of livestock since hundreds of millions of the world's poorest smallholder farmers rely to some extent on livestock for their daily survival; for these farmers mitigating GHG emissions must be seen, and if possible captured, as a cobenefit of more important actions.

\section{INCREASING THE EFFICIENCY OF PRODUCTION}

The decline in emissions intensity points the way for what is likely to be for many the most feasible approach to agricultural GHG mitigation. These reductions have arisen 
largely due to increased efficiency of production (for example, better nutrition, and improved fertilisation practices) and not due to any direct attempt to reduce emissions. There are large differences in efficiency between farms, systems and regions, and in many situations, particularly in developing countries, there is large scope to further decrease emissions intensity via the efficiency route; a route that has synergies with both improved livelihoods and climate change adaptation. Where livestock production is relatively static, increasing efficiency can both reduce emissions per unit of product and absolute emissions. Where the sector is expanding, it will, at a minimum, reduce emissions below 'business as usual'. Increasing efficiency is therefore a key component of agricultural GHG mitigation. Increasing efficiency is also synergistic with development goals and enhancing food security.

The routes for increasing efficiency are well known and, to a large extent, based existing technologies that improve production efficiency at both the individual animal and herd level. The improved availability of better quality feed, improvements in animal health and the use of improved, locally adapted, livestock breeds will improve individual animal and herd performance. All of these will grow productivity at a faster rate than emissions. Manure management practices that improve the recovery and recycling of nutrients can also contribute to mitigation. Understanding and overcoming the barriers to the uptake of these known technologies will be a key challenge.

\section{SPECIFIC MITIGATION TECHNOLOGIES}

In the context of the agreed maximum warming target of $2{ }^{\circ} \mathrm{C}$ agreed in Paris an analysis by Wollenberg et al. (2016) states that "plausible agricultural development pathways with mitigation co-benefits deliver only 21 to $40 \%$ of needed mitigation". While there may be debates around what agriculture's 'share' of any GHG mitigation target should be, this analysis does highlight the fact that relying on improvements in efficiency on their own are unlikely to provide sufficient mitigation from the sector in the context of a $2^{\circ} \mathrm{C}$ maximum warming target. The potential ways in which livestock emissions can reduced have been extensively reviewed elsewhere (Hristov et al. 2013) and will only be briefly summarised here. For tractability, the focus will be on enteric methane and on new technologies.

\section{Dietary approaches}

Changed feeding practices offer what, at first sight, are a relatively straight forward mitigation approach. These can include the feeding of tannin containing plants, sapponins, high lipid diets, high cereal diets, and feeds with high sugar concentrations. The evidence base for the short term efficacy of most of these approaches is reasonably secure although there is less evidence for their longer term efficacy. A bigger issue is perhaps their practicality and affordability. Lipids for example have been found to reduce emissions by about $5 \%$ for every $1 \%$ point increase but unless high lipid by-products are available there is likely to be a cost barrier to their increased use. In addition, there is a fine line between reducing emissions and adversely affecting the ruminants' digestive system. Tannins suffer similar problems; they may consistently reduce methane emissions but they can adversely affect feed intake and are often agronomically poor. The inclusion of cereals at high levels is a well proven methane mitigation route although emissions from growing the cereal crop need to be taken into account; the economics may also be unfavourable in many situations and feeding cereals is impractical for free-ranging animals. Although technically 
promising, it is questionable as to how much mitigation the currently identified feeding approaches will realise in practice.

\section{Modifying rumen processes}

Modifying rumen processes to bring about substantial reductions in $\mathrm{CH}_{4}$ emissions is not new and the testing of halogenated compounds, such as chloroform, was carried out 50 years ago. More modern approaches have targeted the identification of more benign compounds that specifically target the micro-organisms (methanogens) responsible for producing $\mathrm{CH}_{4}$ in the rumen. Hristov et al. (2015) reported the successful testing of one such compound 3-nitrooxy propanol (3NOP) which reduced emissions from lactating dairy cows by $\sim 30 \%$ and had a positive benefit for liveweight gain. The economics and practicality of using such compounds, in particular the mode of delivery, will need to be confirmed but the development of a compound that brings about a substantial reduction in emissions, is animal friendly and appears to have a productivity benefit is a major breakthrough. Researchers in New Zealand and Australia have also been working on stimulating the ruminants' own immune system to produce antibodies that can suppress the activity of methanogens. Success has been reported in vitro (Wedlock et al. 2013) but not so far in vivo. The mode of delivery, the promise of infrequent treatment and the potential applicability to all classes of livestock make this mitigation route highly attractive. However, it is technically challenging and progress has been slow since the initial idea emerged in the mid-1990s.

Another potential novel approach is the use of alternative hydrogen sinks. Methanogens utilise hydrogen as an energy source but there are alternative electron sinks, one of which is the feeding of nitrate (Van Zijderveld et al. 2011a; 2011b), where reduction of up to $50 \%$ have been recorded. Long term studies on both $\mathrm{CH}_{4}$ emissions and animal health are currently lacking. The feeding of nitrates may be attractive where the nitrogen content of the diet is low since protein supplements may already being provided but the economics may be unfavourable.

Modifying rumen microbial processes certainly offers the prospect of large technical reductions in $\mathrm{CH}_{4}$ mitigation but the routes being followed are still in the early stages and for inhibitors and vaccines their commercial availability is still some years away.

\section{Breeding low methane ruminants}

Individual ruminant animals differ in the amount of methane they produce when fed the same quantity of feed and this trait has been found to be heritable. In addition, some animals eat less but achieve the same level of productivity and so will produce less $\mathrm{CH}_{4}$ because of the strong link between intake and $\mathrm{CH}_{4}$. The former approach has been adopted as a direct way of reducing emissions, while the latter is being studied from a productivity and efficiency perspective with a strong $\mathrm{CH}_{4}$ co-benefit. In New Zealand, contrasting high and low $\mathrm{CH}_{4}$ selection lines have been developed with the difference in methane per unit of intake being just under 10\% (Pinares et al. 2013). Animal productivity has not been affected. The $\mathrm{CH}_{4}$ implications of selecting for reduced intake is less well documented but it is a highly attractive route since the primary aim is an increase in productivity. Since continuous improvement in performance via animal breeding is well accepted and highly cost effective the animal breeding route is highly attractive. However, it may not come at a zero cost. Breeding low emitting animals may reduce the progress in other economically important traits and even though breeding for reduced intake is focussed on increased profitability the costs of breeding for the trait can be substantial. 


\section{HOW MUCH DIFFERENCE COULD NEW TECHNOLOGIES MAKE?}

Widespread adoption of an effective vaccine/inhibitor package, together with the breeding of low methane-emitting animals, could deliver large emissions reductions. However, apart perhaps from the breeding of low-emitting sheep, the effectiveness, complementarity, and long-term sustainability of the technologies still have to be demonstrated in real farm situations. Adoption rates will have a big effect on the net emission reductions across the livestock sector. If an inhibitor reduces methane emissions by $30 \%$ but only $10 \%$ of farmers use it, total methane emissions would be reduced by only $3 \%$ (and total GHG emissions reduction would be even smaller because this option would not reduce nitrous oxide). So, the success of new technologies such as vaccines, inhibitors, alternative electron acceptors and low-emissions animals will critically depend on how their widespread adoption can be encouraged; this could mean putting a price on agricultural emissions, something which no country has done to date.

\section{CONCLUSION}

Agricultural GHG emissions from agriculture are an important anthropogenic source of GHG emissions. The livestock sector is responsible almost $75 \%$ of these emissions. Estimating emissions from agriculture is challenging and all estimates are subject to considerable uncertainty. At the individual country level, using IPCC Tier 1 approaches has severe limitations and the use of Tier 2 approaches is encouraged since these improve accuracy and transparency, incorporate changes in animal productivity, facilitate the prioritisation of resources and allow changes in emissions intensity to be better quantified.

For many countries changes in the efficiency of production provide the best opportunity to reduce emissions; emission reductions being a co-benefit of broader social and economic development goals. Mitigation via improved efficiency is unlikely to provide enough mitigation by itself for agriculture to reduce emissions below current levels because of the increase in demand for livestock products. New technologies are under development that can potentially allow agriculture to make a much greater mitigation contribution although they face technical, economic and practical challenges.

\section{REFERENCES}

FAO. 2011. World livestock 2011 - Livestock in food security. Rome (Italy): FAO.

Hristov AN, Oh J, Lee C, Meinen R, Montes F, Ott T, Firkins J, Rotz A, Dell C, Adesogan A, Yang W, Tricarico J, Kebreab E, Waghorn G, Dijkstra J, Oosting S. 2013. Mitigation of greenhouse gas emissions in livestock production - A review of technical options for non- $\mathrm{CO}_{2}$ emissions. In: Gerber PJ, Henderson B, Makkar HPS, editors. Animal production and health paper no. 177. Rome (Italy): FAO.

Hristov AN, Oh J, Giallongo F, Frederick TW, Harper MT, Weeks HL, Branco AF, Moate PJ, Deighton MH, Williams SRO, Kindermann M, Duval S. 2015. An inhibitor persistently decreased enteric methane emission from dairy cows with no negative effect on milk production. Proc Natl Acad Sci USA. 112:10663-10668.

IPCC. 2006. IPCC guidelines for national greenhouse gas inventories. In: Eggleston HS, Buendia L, Miwa K, Ngara T, Tanabe K, editors. Volume 4. Agriculture, forestry and other land use. Tokyo (Japan): Institute for Global Environmental Strategies.

Ministry for the Environment. 2016. New Zealand greenhouse gas inventory report 1990-2014. CRF Tables. [Internet]. [cited 1 August 2016]. Available from http://www.mfe.govt.nz/sites/ default/files/media/Climate\%20Change/national-inventory-report-2016.pdf 
Pinares CS, Hickey EA, Young EA, Dodds KG, MacLean S, Moland G, Sandoval E, Kjestrup H, Harland R, Hunt C, Pickering NK, McEwan JC. 2013. Heritability estimates of methane emissions from sheep. Animal. 72:316-321.

Smith P, Bustamante M, Ahammad H, Clark H, Dong H, Elsiddig EA, Haberl H, Harper R, House J, Jafari M, Masera O, Mbow C, Ravindranath NH, Rice CW, Abad CR, Romanovskaya A, Sperling F, Tubiello F. 2014. Agriculture, forestry and other land use (AFOLU). In: Edenhofer O, Pichs-Madruga R, Sokona Y, Farahani E, Kadner S, Seyboth K, Adler A, Baum I, Brunner S, Eickemeier P, Kriemann B, Savolainen J, Schlömer S, von Stechow S, Zwickel T, Minx JC, editors. Climate change 2014: Mitigation of climate change. Contribution of working group iii to the fifth assessment report of the intergovernmental panel on climate change. Cambridge (UK): Cambridge University Press.

Wedlock DN, Janssen PH, Leahy SC, Shu D, Buddle BM. 2013. Progress in the development of vaccines against rumen methanogens. Animal. 7:244-252.

Wollenberg E, Richards M, Smith P, Havlík P, Obersteiner M, Tubiello FN, Herold M, Gerber P, Carter S, Reisinger A, van Vuuren DP, Dickie A, Neufeldt H, Sander BO, Wassmann R, Sommer R, Amonette JE, Falcucci A, Herrero M, Opio C, Roman-Cuesta RM, Stehfest E, Westhoek H, Ortiz-Monasterio I, Sapkota T, Rufino MC, Thornton PK, Verchot L, West PC, Soussana JF, Baedeker T, Sadler M, Vermeulen S, Campbell BM. 2016. Reducing emissions from agriculture to meet the $2^{\circ} \mathrm{C}$ target. Glob Chang Biol. 19:988-995.

Van Zijderveld SM, Fonken B, Dijkstra J, Gerrits WJJ, Perdok HB, Fokkink W, Newbold JR. 2011a. Effects of a combination of feed additives on methane production, diet digestibility, and animal performance in lactating dairy cows. J Dairy Sci. 94:1145-1454.

Van Zijderveld SM, Gerrits WJJ, Dijkstra J, Newbold JR, Hulshof RBA, Perdok HB. 2011b. Persistency of methane mitigation by dietary nitrate supplementation in dairy cows. J Dairy Sci. 94:4028-4038.

\section{DISCUSSION}

\section{Questions}

1. If technologies of mitigation applied, will it affect the feeding system in reducing GHG?

2. Livestock has been blame as suspect to global warming, how the mitigation of GHG in smallholder farmer meet recomendation for government?

3. Can government subsidies for farmer who applied Biogas system in their farm improve mitigation from livestock?

4. You mention about the selection of breed that low $\mathrm{CH}_{4}$ production, but did not mention about their productivity.

5. If you combine between selected genetic and feeding system, what is your expectation from the farmer, because mostly farmers don't care about reducing $\mathrm{CH}_{4}$ ?

\section{Answers}

1. There are two types of feeds can reduce $\mathrm{CH}_{4}$, grain and grass. Selection of mitigation technique to reduce $\mathrm{CH}_{4}$, must be appropiate approach to the production system. Reducing GHG just from feed will be difficult because many variation of feed quality available in the world. Therefore the reducing must be presented as animal production, thus the quality of feed must be increased, not by using specific feed that can reduce $\mathrm{CH}_{4}$. 
2. In principal, mitigation must be meet both an improvement of animal production and $\mathrm{CH}_{4}$ reduction.

3. Biogas is an easy technology for manure management, but the important is how to push the farmer motivation to adopt biogas technology, because when the subsidy is stoped, then the farmer will also stop using the biogas. If government will provide subsidy for biogas, it must be in longer period.

4. Breed selection is an expensive process. For developing countries can be used more general breeding improvement. Becaue breed not directly reduce $\mathrm{CH}_{4}$. Low $\mathrm{CH}_{4}$ produced more caused by small rumen of the animals thus consume smaller number of feed.

5. Farmer will feed their animals with good quality feed which will reduce $\mathrm{CH}_{4}$ production. 